\title{
Homologação das Decisões do Conselho de SAÚdE ${ }^{(*)}$
}

José Valdemiro de Melo ${ }^{(*)}$

\section{RESUMO}

O estudo em questão pretende analisar as implicações que a falta de homologação das decisões do Conselho de Saúde acarretam. Esta análise fez-se partindo de uma breve conceituação de Estado Moderno e sua função em face da ordem constitucional instaurada pela Constituição Federal Brasileira de 1988, notadamente com relação aos direitos fundamentais. Versa sobre o modo como a Carta Política tratou do tema da saúde, enquanto direito social de relevância pública, bem como os mecanismos por ela desenhados como viabilizadores da direito à saúde, chegando-se até o papel dos ConseIhos de Saúde como mecanismo de controle social e, assim, discorrendo sobre a falta de homologação de suas decisões, indo de encontro à própria ordem constitucional instaurada e os valores que ela abarca.

\section{Descritores}

Direitos fundamentais; Relevância pública; Direito à saúde; Controle social; Conselho de Saúde; Direito Sanitário; Saúde pública.

\section{ABSTRACT}

The present study intends to analyze the lack of homologation of Health Counsel's decisions and its consequences. This analysis begins with a

${ }^{*}$ ( ) Baseado no trabalho de monografia apresentado para conclusão do Curso de Especialização a distância em Direito Sanitário para Membros do Ministério Público e da Magistratura Federal.

(**) Promotor de Justiça membro do Ministério Público do Estado do Ceará, com atuação na Promotoria da Fazenda Pública. E-mail: josedmelo @ hotmail.com - Recebido em 05-05-2003. Aprovado em 09-06-03. 
brief concept of the Modern State and its function faced to the constitutional order. restored by the 1988's Brazilian Federal Constitution, mainly about its relation with basic rights. This study examines the way health is conceived as a social right of public relevance at the Constitution, as well as the mechanisms drawn to operate it as right. It also examines the Health Counsel's function as "social controller" and, by discussing the lack of homologation of its decisions, shows the unconstitutionality of this measure before the values abridged by the 1988's Brazilian Constitution.

\section{Key-words}

Basic Rights; Public Relevance; Right to the Health; Social Control; Health Counsel; Health Law; Public Health.

\section{INTRODUÇÃO}

O presente artigo destina-se a analisar a incompatibilidade do exercício simultâneo das funções de Chefe do Poder Executivo ou do titular da pasta de saúde (ministro ou secretário de saúde) com a de presidente do Conselho de Saúde, considerando a existência de um conflito de interesses, em estado potencial, presente em cada reunião, que por certo virá a tona quando as resoluções do Conselho conflitarem com os planos de governo ou com a política de gestão para a pasta de saúde, ocasionando, assim, situações de risco de violação da lei, incluindo-se aí a própria sistemática da Constituição de 1988, do Sistema Único de Saúde, dos direitos dos cidadãos às ações e aos serviços de saúde, do próprio Conselho de Saúde e dos agentes envolvidos no fato.

A proposta do tema do Artigo nasceu da constatação das conseqüências danosas, para o Sistema de Saúde (SUS), geradas pela não homologação da resolução do Conselho por parte de seu presidente, ato necessário para a publicação e também para que a mesma produza os efeitos que Ihe são próprios. A não homologação gera ainda desmotivação e desprestígio dos integrantes do Conselho, que ficam expostos frente aos representados quando os mesmos manifestarem sua insatisfação por não constatarem melhorias nas ações e serviços de saúde de suas localidades.

A ausência de homologação da decisão do Conselho de Saúde, ao nosso sentir, conflita com o caráter de relevância pública atribuído às ações e serviços de saúde, pela Carta Magna de 5 de outubro de 1988, como direito social, visando a realização dos objetivos fundamentais da República Federativa do Brasil, na promoção do bem comum de todos, não sendo permitido ao Ministério Público, incumbido que foi de fiscalizar e zelar para o integral cumprimento deste direito, se manter alheio ou à margem deste assunto. 
A Constituição Federal, no campo da saúde, nos artigos regulamentados pelas Leis ns. $8.080 / 90$ e $8.142 / 90$, assegura o princípio para a criação dos instrumentos de descentralização político-administrativa, abre os espaços para serem disciplinadas as formas de decidir, agir, e outras ações, permitindo ao cidadão, como agente de formação e de transformação da realidade social e política do País, a oportunidade de lutar pela concretização dos direitos já conquistados e da criação de novos direitos.

\section{O PAPEL DO ESTADO BRASILEIRO MODERNO EM FACE DOS DIREITOS FUNDAMENTAIS}

O Estado pode ser conceituado como a sociedade politicamente organizada para atender ao bem comum. É ele tido como a forma mais perfeita de organização social engendrada pelo homem. Tem, nos dias de hoje (Estado Moderno), como principal e permanente fim, a realização do bem comum (razão teleológica - segundo doutrina Pedro Salvetti Netto). O Estado é tido como um implementador de políticas públicas, econômico-sociais, aptas a atender o interesse social.

No exercício de tal função, verdadeiro dever-poder, abre-se ao Estado, em determinadas situações, um poder discricionário e mesmo limitador de direitos individuais como forma de viabilizar o exercício desse seu papel ativo, implementador em prol do bem comum, v. g., a compulsoriedade de vacinação coletiva para evitar-se surto epidêmico, o fechamento de indústria poluidora para tutela da saúde pública, a obrigatoriedade do ensino primário, para amparo da educação(1).

E isto se confirma quando se analisa a atual Constituição da República Federativa do Brasil que, em seu no Título II, trata dos direitos e garantias fundamentais e, a partir das suas existências, delimita a ação do Poder Público e enseja garantias a todos aqueles que se encontram sob sua proteção.

Segundo Alexandre de Moraes, a doutrina moderna classifica os direitos fundamentais como de primeira, segunda e terceira gerações, baseando-se na ordem histórica cronológica em que passaram a ser constitucionalmente reconhecidos. E cita trecho do pronunciamento do Ministro do Supremo Tribunal Federal, Celso de Mello, lançado por ocasião de julgamento na Suprema Corte Brasileira: "enquanto os direitos de primeira geração (direitos civis e políticos) - que compreendem as liberdades clássicas, negativas ou formais - realçam o princípio da liberdade e os direitos de segunda geração (direitos econômicos, sociais e culturais) - que se identificam com as liberdades positivas, reais ou concretas - acentuam 0

(1) SALVETTI NETTO, Pedro. Curso de ciência política. São Paulo: Hemeron Ed., 1977. p. 67. 
princípio da igualdade, os direitos de terceira geração, que materializam poderes de titularidade coletiva atribuídos genericamente a todas as formações sociais, consagram o princípio da solidariedade e constituem um momento importante no processo de desenvolvimento, expansão e reconhecimento dos direitos humanos, caracteriza-os enquanto valores fundamentais indisponíveis pela nota de uma essencial inexauribilidade ${ }^{(2)}$.

\section{DIREITO À VIDA}

Dentre os direitos constitucionais, o direito à vida (segunda geração) é o mais fundamental dos direitos, conforme consenso da doutrina, por se constituir em condição necessária para o exercício de todos os demais direitos, cabendo ao Poder Público a garantia de seu exercício.

Para garantir o direito à vida, o direito à vida digna em saúde, é preciso, além da assistência médica e hospitalar, garantir também condições básicas para que as pessoas não fiquem doentes. Nesse sentido leciona Alexandre de Moraes que a Constituição Federal não só garantiu o direito à vida, como remeteu ao Estado o dever de assegurá-lo em sua dupla acepção, a primeira relacionada ao direito de continuar vivo, protegido desde a vida uterina e a segunda de ter uma vida digna, tudo sob a proteção do princípio da isonomia ou da igualdade.

\section{DIREITO À SAÚDE - ESCORÇO HISTÓRICO}

A Professora Sueli Gandolfi Dallari, com a salutar cátedra que lhe é peculiar, esclarece que o conceito de saúde pública começou a ser delineado no Renascimento, época em que por não ser a saúde um conceito científico, e sim uma idéia comum, houve uma aproximação dela com a de exercício físico (ginástica) e com a dieta. Platão ampliou a idéia com a inclusão do campo da alma e a necessidade de que a mesma mantenha relação adequada com o corpo.

$\mathrm{Na}$ Renascença, o conceito sofre uma nova ampliação com o tratamento dos pobres em domicílio ou nos hospitais pelas cidades, aumentando o seu poder de higiene e favorecendo a limpeza e os exercícios corporais dos habitantes.

O início do século $\mathrm{XX}$ encontra a saúde ao abrigo da proteção sanitária como política de governo, hierarquizada em três formas: primária, com suas ações voltadas para a eliminação das causas e condições que favorecem o

(2) MELLO, Celso. STF-Pleno-MS/SP 22.164. Diário da Justiça, Seção I, 17 nov. 1995, p. 39206. 
aparecimento de doenças, agindo sobre o meio ambiente; secundária, com ações dirigidas a evitar o aparecimento de doenças determinadas, por meio de vacinação, dos controles de doenças etc.; finalmente, a terciária, que visa limitar a importância das incapacidades crônicas.

Ao findar referido século $\mathrm{XX}$, a sociedade já contempla uma nova visão da saúde pública, agora sob o enfoque dos comportamentos individuais, com prevalência da idéia de que a proteção contra a doença é de responsabilidade individual e que os grupos - de doentes ou portadores do vírus ou de familiares ou amigos deles - devem organizar a prestação dos cuidados de saúde, ficando o Estado, com papel subsidiário da responsabilidade pelo controle da qualidade do sangue. Para as estruturas estatais de prevenção sanitária as prioridades não mais se darão em função dos dados epidemiológicos, e sim em virtude da análise econômica custo-benefício, em prejuizo das ações de prevenção, elemento historicamente essencial ao conceito de saúde pública(3).

A saúde, como direito social, por sinal de grande importância para a existência da vida, foi eleita como de relevância pública pelo legislador constituinte de 1988. Saúde, condição exigida para uma vida saudável, passaporte para o exercício das demais formas de direitos, garantida pela Constituição da República, cujo art. 196 consagra a todos os brasileiros o direito universal e gratuito às ações e aos serviços a ela relacionados.

\section{RELEVÂNCIA PÚBLICA}

Cabe aqui um esclarecimento. O termo relevância pública, acima empregado, no sentido a ele dado pela Constituição Federal, respeitadas a abrangência e a liberdade semântica e sem cometer heresia conceitual, quer significar "aquilo que é de grande valor para o povo, para a coletividade". Por conta desta qualificação no campo das ações e serviços de saúde e em virtude da sua importância para a vida humana, os Poderes Públicos deverão dar proeminente atenção a este setor, em comparação a alguns dos demais direitos fundamentais.

Como conseqüências do conteúdo da expressão "de relevância pública" com que foram distinguidos os serviços e ações de saúde, cabe destacar: a) prioridade nas ações de planejamentos e/ou gerenciamento para a área, por parte dos gestores e Poderes Públicos; $b$ ) atenção especial e prioridade no zelo e na fiscalização pelo Ministério Público, adotando as medidas necessárias para a sua efetiva prestação; c) legitimação do Minis-

(3) DALLARI, Sueli Gandolfi. Direito sanitário. In: MANUAL Conceitual do Curso de Especialização a distância em Direito Sanitário, para membros do Ministério Público e da Magistratura Federal. Brasília: Ed. UnB; FIOCRUZ. 
tério Público para o enfrentamento preventivo ou repressivo, judicial ou extrajudicialmente, prioritariamente, em face da omissão do Poder Público; d) a disponibilização dos serviços, sem distinção de posses ou classes (tratamento e uso de todos e por todos); e) as ações e serviços de saúde compõem o rol de atividades-fim do Estado Democrático de Direito.

\section{CONTROLE SOCIAL COMO FORMA DE IMPLEMENTAÇÃO DE POLITICAS PÚBLICAS E EFETIVAÇÃO DOS DIREITOS FUNDAMENTAIS}

O controle social na área da saúde deve ser entendido como o intervir e o interagir da sociedade, representada em todos os seus seguimentos junto ao Estado, na gestão das políticas pública da saúde de forma permanente em benefício do conjunto da sociedade, a ser construída de forma justa, livre e solidária, para a edificação dos direitos e deveres inerentes à própria condição humana.

A função do controle social é a de adequar o comportamento do homem à ordem social. Em um primeiro aspecto, esse controle pode advir da natureza interior do indivíduo, o chamado controle ético, formado a partir da socialização que interiorizou ou da consciência que carrega em seu íntimo, que comanda o discernimento entre a conduta certa e a errada, para valorar o comportamento social a ser aflorado.

$\mathrm{Na}$ ausência do controle social de forma pessoal, o freio advém do receio da observação no ato da transgressão. Quando a manifestação do controle social é realizada fora do indivíduo, por outros indivíduos, grupo social ou representante da comunidade organizada, que emprega servidores especiais da vigilância, instrumentos e força coercitiva para manter o bom comportamento social do individuo, de forma que assegure a paz, a ordem, o progresso e a realização do bem comum, o controle organizado tem natureza externa e seus aspectos são formais.

Da análise dos aspectos internos ou externos dos referidos controles, destaca-se, como ponto comum entre eles, ser o próprio indivíduo o objeto ou sujeito passivo deste controle, cuja aferição da conduta pela sociedade, a partir de um conjunto de instrumentos utilizado pelo grupo (poder público) ou por seus mandatários (poder político) para fiscalizar, dirigir ou restringir os atos ou a conduta das pessoas.

Com a migração da população para a periferia das grandes cidades, acentuando as desigualdades sociais, agravando os problemas urbanos, sindicatos, associações de moradores, entidades filantrópicas, entidades religiosas e muitas outras organizações até então ausentes, passaram a pressionar o poder público, para melhores condições de vida, principalmente nas áreas de saúde, educação, segurança, moradia e muitas outras em favor dos direitos de cidadania do conjunto da sociedade. 
Este movimento fez nascer uma terceira forma de controle social (ação cidadã): um controle exercido pela própria sociedade em face do Estado através de mecanismos organizados. E o faz por meio de instrumentos legais próprios extraídos da Constituição Federal de 1988 e da legislação infraconstitucional.

Nesse contexto, é de se ressaltar o papel do Ministério Público, que tem como função institucional zelar pelos serviços de relevância pública, dentre os quais as ações e serviços de saúde, adotando as medidas necessárias para sua efetiva prestação, inclusive em face de omissão do Poder Público(4).

\section{MECANISMOS DE CONTROLE SOCIAL: CONSELHOS DE SAÚDE}

Com o advento da Constituição Federal de 5 de outubro de 1988, que instituiu o Estado Democrático de Direito, este tendo como fundamentos a soberania, a cidadania, a dignidade da pessoa humana, os valores sociais do trabalho e da livre iniciativa e o pluralismo político, conforme ficou devidamente registrado em seu art. $1^{\circ}$, neste espírito de valorização do social, a saúde recebeu tratamento especial e passou a ser direito universal de todos os brasileiros.

As ações e serviços de saúde, como direito público subjetivo, com distinção própria em relação aos demais direitos sociais, por vontade expressa da Constituição Federal, que conferiu aos mesmos a qualidade de relevância pública e impôs ao Estado o dever de prestá-los a toda a população, dispõem também dos mecanismos de organização e controle social para o exercício das ações administrativas.

As diretrizes traçadas agrupam as ações e serviços de saúde em um Sistema Único (SUS), com ações de comando regionalizadas e hierarquizadas, com direção única em cada um dos níveis ou esferas de governo. Asseguram atendimento integral, gratuito, serviços assistenciais, com prioridade para as ações preventivas e a participação da comunidade (art. 198).

Para dar cumprimento ao preceito constitucional da saúde como direito social de cada um e de todos os brasileiros, foi promulgada a Lei n. $8.080 /$ 90 que dispõe sobre as condições para a promoção, proteção e recuperação da saúde, a organização e o funcionamento dos serviços a serem prestados por pessoas físicas ou jurídicas de direito público e privado.

Com a promulgação da Lei n. $8.142 / 90$ foi assegurada a participação da comunidade na gestão do SUS, através dos Conselhos de Saúde, da formulação de políticas de saúde, controle, fiscalização e acompanhamento das ações e serviço de saúde.

(4) DALLARI, Sueli Gandolfi. op. cit. 
O Conselho de Saúde, para a fonte normativa que o instituiu (Lei $n$. 8.142, de 28 de dezembro de 1990), é um órgão permanente, colegiado, deliberativo, composto por representantes do governo, prestadores de serviço, profissionais de saúde e usuários; atua na formulação de estratégias e no controle da execução da política de saúde na instância correspondente, inclusive nos aspectos econômicos e financeiros, cujas decisões serão homologadas pelo chefe do poder legalmente constituido em cada esfera de governo (art. $1^{\circ}, \S 2^{\circ}$ ).

\section{COMPOSIÇÃO DOS CONSELHOS DE SAÚDE}

Os Conselhos de Saúde são instâncias colegiadas e espaço democrático destinado à participação popular para a discussão da política de saúde.

Sobre a definição, estrutura, composição e competência dos Conselhos de Saúde, o assunto está didaticamente exposto no Guia do Conselheiro Curso de Capacitação de Conselheiros Estaduais e Municipais. Edição 2002 do Ministério as Saúde, conforme a seguir lançado: "Com base na legislação existente, pode-se definir um Conselho de Saúde como um órgão ou instância colegiada de caráter permanente e deliberativo, em cada esfera de governo, integrante da estrutura básica da Secretaria ou Departamento de Saúde dos estados e municípios, com composição, organização e competência fixada em lei. O Conselho consubstancia a participação da sociedade organizada na administração do Sistema de Saúde, propiciando o controle social desse sistema".

Recomenda, ainda, que o número de Conselheiros não seja inferior a 10 nem superior a 20 membros. A situação de cada Estado e Município e a discussão com os segmentos que participarão do Conselho levarão à meIhor definição dessa composição numérica. A representação de órgãos e/ ou entidades que será apresentada, a seguir, como exemplo, poderá sofrer modificações de acordo com a realidade existente em cada Estado, Município e no Distrito Federal, preservando-se, porém, o princípio da paridade em relação aos usuários.

Em relação aos Conselhos Estaduais de Saúde: representante(s) do governo federal, indicado(s) pelo Ministro da Saúde e outros Ministérios; representante da Secretaria de Saúde do Estado; representante(s) das Secretarias Municipais de Saúde; representante(s) dos trabalhadores na área de saúde; representante(s) de prestadores de serviço de saúde, sendo $50 \%$ de entidades filantrópicas e $50 \%$ de entidades não filantrópicas;

A representação dos usuários deverá ser composta por: representante(s) de entidades congregadas de sindicatos de trabalhadores urbanos e ru- 
rais; representante(s) de movimentos comunitários organizados na área da saúde; representante(s) de conselhos comunitários, associações de moradores ou entidades equivalentes; representante(s) de associações de portadores de deficiências; representante(s) de associações de portadores de patologias; representante(s) de entidades de defesa do consumidor.

A representação total dos Conselhos deve ser distribuída da seguinte forma: $50 \%$ de usuários, $25 \%$ de trabalhadores de saúde e $25 \%$ de prestadores de serviços (públicos e privados). Os representantes dos usuários deverão ser indicados impreterivelmente pelas suas entidades.

Em relação aos Conselhos Municipais de Saúde, propõe-se uma composição semelhante à dos Conselhos Estaduais, adaptada ao Município. Geralmente, não será necessária a presença de representante do governo federal, a não ser em casos especiais que serão definidos localmente. Os usuários terão representação semelhante à dos Conselhos Estaduais. Os outros segmentos deverão ser representantes do governo estadual, do governo municipal, dos trabalhadores da área da saúde e dos prestadores de serviços de saúde de entidades filantrópicas e não filantrópicas.

Nenhum Conselheiro poderá ser remunerado pelas suas atividades, haja vista serem elas consideradas de relevância pública.

\section{ESTRUTURA DOS CONSELHOS DE SAÚDE}

Os organismos de Governo Estadual e Municipal deverão dar apoio e suporte administrativo para a estruturação e funcionamento dos ConseIhos, garantindo-Ihes dotação orçamentária.

O Conselho de Saúde deverá ter como órgãos o Plenário e o Colegiado Pleno e uma Secretaria Executiva com assessoria técnica. O Plenário ou o Colegiado Pleno será composto pelo conjunto de Conselheiros.

Os atos dos Conselhos serão homologados pelo chefe do Poder Executivo local, podendo esta atribuição ser delegada aos respectivos Secretários Estadual e Municipal, conforme o caso.

O Plenário reunir-se-á, obrigatoriamente, uma vez ao mês e, extraordinariamente, sempre que necessário, e funcionará baseado em Regimento Interno a ser elaborado e aprovado pelo próprio Plenário. A Secretaria Executiva deverá ser a unidade de apoio ao funcionamento do Conselho de Saúde, secretariando suas reuniões e servindo de instrumento divulgador de suas deliberações, mantendo intercâmbio constante com as unidades do Sistema Único de Saúde e articulando os entendimentos necessários ao seu aprimoramento. Para tal, deverá contar com pessoal administrativo e pessoal técnico, que funcionará como Assessoria Técnica ao Plenário e mobilizará consultorias e assessoramento a serem fornecidos por parte 
das instituições, órgãos e entidades da área de saúde que possam dar suporte e apoio técnico ao Conselho de Saúde. Os órgãos do Governo Estadual e/ou Municipal devem prestar apoio, informações e assessorias aos Conselhos de Saúde. As dimensões de cada estrutura da Secretaria Executiva componente do Conselho Estadual ou Municipal de Saúde deverão ser discutidas e definidas caso a caso, para evitar-se superdimensionamento. A Secretaria Executiva está subordinada ao Plenário do Conselho.

$O$ ato de criação do Conselho de Saúde, bem como sua composição, organização, estrutura e competência, deverá ser estabelecido por lei estadual ou municipal, e referendado pelo Poder Executivo correspondente, que nomeará os Conselheiros indicados pelos órgãos e entidades. $O$ mandato dos Conselheiros será definido no Regimento Interno, não devendo coincidir com o mandato do governo estadual ou municipal, sugerindo-se que tenha a duração de dois anos, podendo ser reconduzido a critério das respectivas representações (IX Conferência Nacional de Saúde). O Regimento Interno de cada Conselho também definirá o quórum mínimo para o caráter deliberativo das reuniões do Plenário e para as questões de suplência e perda do mandato por faltas justificadas. Os Conselheiros têm autonomia de se autoconvocar. Suas reuniões devem ser abertas ao público, com pauta e datas previamente divulgadas pela imprensa.

\section{COMPETÊNCIA DOS CONSELHOS DE SAÚDE}

Os Conselhos de Saúde Estaduais, Municipais e do Distrito Federal, que têm algumas competências já definidas nas leis federais e complementadas pelas legislações estaduais e municipais, poderão, ainda: atuar na formulação e controle da execução da política de saúde, incluídos seus aspectos econômicos, financeiros e de gerência técnico-administrativa; estabelecer estratégias e mecanismos de coordenação e gestão do SUS, articulando-se com os demais colegiados em nível nacional, estadual e municipal; traçar diretrizes de elaboração e aprovar os planos de saúde, adequando-os às diversas realidades epidemiológicas e à capacidade organizacional dos serviços; propor a adoção de critérios que definam qualidade e melhor resolubilidade, verificando o processo de incorporação dos avanços científicos e tecnológicos na área; propor medidas para o aperfeiçoamento da organização e do funcionamento do Sistema Único de Saúde (SUS); examinar propostas e denúncias, responder a consultas sobre assuntos pertinentes a ações e serviços de saúde, bem como apreciar recursos a respeito de deliberações do Colegiado; fiscalizar e acompanhar o desenvolvimento das ações e serviços de saúde; propor a convocação e estruturar a comissão organizadora das Conferências Estaduais e Municipais de Saúde; fiscalizar a movimentação de recursos repassados à Secretaria de Saúde e/ou ao Fundo de Saúde; estimular a participação comunitá- 
ria no controle da administração do Sistema de Saúde; propor critérios para a programação e para as execuções financeira e orçamentária dos Fundos de Saúde, acompanhando a movimentação e destinação de recursos; estabelecer critérios e diretrizes quanto à localização e ao tipo de unidades prestadoras de serviços de saúde públicos e privados, no âmbito do SUS; elaborar o Regimento Interno do Conselho e suas normas de funcionamento; estimular, apoiar ou promover estudos e pesquisas sobre assuntos e temas na área de saúde de interesse para o desenvolvimento do Sistema Único de Saúde; outras atribuições estabelecidas pela Lei Orgânica da Saúde e pela IX Conferência Nacional de Saúde"(5).

\section{DISCUSSÃO ESPECÍFICA ACERCA DO TEMA PROPOSTO}

Quando o ser humano, a partir de determinado momento na história, abriu mão de parte da liberdade que possuía em seu estado de natureza para colocá-la sob limites de uma autoridade central, tinha como objetivo alcançar a felicidade na terra, na forma de bem-estar, dignidade da pessoa humana, segurança pessoal e da propriedade, paz e outros valores que elegeu como importantes.

A Constituição da República Federativa do Brasil, no preâmbulo, de maneira expressa, firmou o compromisso de instituir um Estado Democrático de Direito, destinado a assegurar o exercício dos direitos sociais e individuais, a liberdade, a segurança, o bem-estar, o desenvolvimento, a igualdade e a justiça como valores supremos de uma sociedade fraterna, pluralista e sem preconceitos, fundada na harmonia social. Conferiu ao Estado o dever de tornar concreto e assegurar ao cidadão o exercício livre destes direitos.

Ao estabelecer as diretrizes da instituição da ordem social, matéria do campo dos direitos sociais e todos vinculados à esfera dos princípios fundamentais, determinou que a mesma deveria ser organizada com a observância do bem-estar e a justiça social, onde ficassem assegurados os direitos relativos à saúde, à previdência e à assistência social (arts. 94 e 193, da CF/88). Definiu serem de relevância pública as ações e serviços de saúde (art. 197, da CF/88). Garantiu a participação popular no Sistema Único de Saúde (art. 198, III, da CF/88).

Ao entrarem no cenário jurídico as Leis ns. $8.080 / 90$ e $8.142 / 90$, ficou ali expresso e assentado que a participação da comunidade nas ações e serviços de saúde se daria através das Conferências e Conselhos de Saúde, a primeira com a finalidade de a cada quatro anos avaliar a situação de saúde

(5) GUIA do Conselheiro. Curso de Capacitação de Conselheiros Estaduais e Municipais - 2002MS. p. 161-162. 
e propor as diretrizes para a formulação da política de saúde e o segundo para atuar na formulação de estratégias e no controle da execução da política de saúde, inclusive nos aspectos econômicos e financeiros.

A escolha do título deste estudo, "A falta de homologação das decisões do conselho de saúde - implicações", decorreu do nosso interesse pelo assunto saúde em razão das atividades profissionais exercidas. Como Promotor de Justiça do Ministério Público do Estado do Ceará, com exercício na Promotoria da Fazenda Pública, local por onde têm curso as ações judiciais de interesse do Estado do Ceará, do Município de Fortaleza e suas autarquias, o episódio dengue, que envolveu muitos Estados da Federação, resultou na aceleração e ampliação dos estudos para os problemas da saúde, exigindo maior atenção e aperfeiçoamento em nossa atuação como Ministério Público agente.

Da estrutura do SUS voltamos nossa atenção para os Conselhos de Saúde, por serem os mesmos instrumentos do controle social para o controle público.

Nas visitas realizadas em alguns Conselhos, verificou-se em expressiva parte deles, a exemplo dos Conselhos locais, a presença de problemas de funcionalidade, a partir da falta de estrutura, com a improvisação de espaço físico e de infra-estrutura para a realização das reuniões.

Esta falta de estrutura, esta forma de improvisação de local para a realização das reuniões, apesar da boa vontade dos Senhores Conselheiros, dificultava o exame adequado dos assuntos da pauta, principalmente por se pedir urgência na análise da matéria, ocasionando desestímulo na atuação dos mesmos.

Constatou-se um segundo elemento desagregador, este por sinal muito grave, materializado na falta de homologação das decisões dos Conselhos de Saúde. A ausência da homologação ocorria mediante recusa expressa ou de forma tácita, na qual o tempo se encarregava de concretizar a omissão. Havia também os casos em que o documento era assinado, em arremedo de cumprimento da Lei, porém os demais atos administrativos necessários para a publicidade e execução das decisões não ocorriam.

As razões que ensejaram as recusas em homologar as resoluções, se apoiavam no temor do Presidente do Conselho de que, após a homologação, a sua execução poderia causar embaraços ou dificuldades de gestão, pelo fato de o conteúdo da decisão conflitar, total ou parcialmente, com as diretrizes ou políticas de gestão da sua pasta de saúde.

Essa espécie de omissão do Poder Público em confirmar o conteúdo de um documento do Colegiado, cujo ato homologatório decorre de imposição legal, onde a Lei não contempla oportunidade de recusa ou de protelamento configura: 
- atentado contra os anseios que motivaram o homem a abrir mão de seu estado de natureza, para se colocar sob os limites de uma autoridade central, visando alcançar a felicidade na terra, nas suas diversas formas e valores;

- agride os objetivos da República Federativa do Brasil de construir um Estado Democrático de Direito, destinado a assegurar o exercício dos direitos sociais e individuais, os valores básicos de uma sociedade fraterna, fundada na harmonia, na cidadania, na dignidade da pessoa humana, na valorização do trabalho, na erradicação da pobreza, da marginalização, etc., conforme compromisso da Constituição Federal, a partir do seu preâmbulo;

- viola os objetivos da Ordem Social onde prevê que o Sistema Único de Saúde, ao organizar, deverá observar o bem-estar, a justiça social, de forma que fiquem assegurados os direitos relativos às ações e aos serviços de saúde, na forma de acesso universal, isonomia de tratamento, gratuidade, para todos os brasileiros e estrangeiros residentes no País, assegurada a participação popular;

- produz prejuízos ao exercício da cidadania no momento em que impede que a voz e a vez do Conselho de Saúde, expressas na resolução, resultado do agir do controle social sobre o controle público e da deliberação do colegiado, conseqüência também da fiscalização da execução da política de saúde, sucumbam junto o caráter de relevância pública, frente ao planejamento administrativo para a área de saúde;

- desrespeita a luta popular, o trabalho dos anônimos bandeirantes da saúde e das causas sociais, que de suas trincheiras na cidade, no campo, nas universidades, nos hospitais ou em qualquer outro lugar, não temeram as lágrimas nem os gritos, não calaram a voz, combatendo o bom combate na defesa dos ideais da causa justa, da justiça social, no afã da realização dos objetivos da República Federativa do Brasil para a construção do Estado Democrático de Direito.

\section{CONCLUSÕES}

De todo o exposto, as conclusões são no sentido de que:

1) os Conselhos de Saúde tenham autonomia administrativa e financeira, com orçamento próprio, espaço físico e instalações adequadas, pessoal de apoio administrativo e técnico, para uma atuação eficiente;

2) haja alteração na Lei n. 8.142/90, fazendo constar na mesma, como diretriz nacional, que as criação de novos Conselhos de Saúde, com a alteração dos diplomas já existentes, observem o processo do exercício demo- 
crático do voto de todos os Conselheiros, com vinculação da homologação das resoluções à presidência do órgão, quando da escolha do presidente e mesa diretora do Conselho de Saúde.

Cabe aqui o registro de que os Estados do Paraná e do Rio Grande do Sul e alguns Municípios já adotam o sistema de eleição direita, e mesmo para estes as dificuldades operacionais dos Conselhos não ficaram imunes aos problemas de funcionalidade principalmente quando o Secretário de Saúde ou o Chefe do Executivo é o candidato derrotado no processo de escolha.

Até mesmo o Conselho Nacional de Saúde, apesar da sua Resolução n. 33/92 recomendar a eleição direta para a Presidência do Conselho, não providenciou a devida alteração no diploma normativo de sua criação e continua sendo presidido pelo senhor Ministro da Saúde.

3) ao se promover a alteração da Lei 8.142/90, contemple a mesma, também como diretriz nacional, sanção administrativa protetora das decisões dos Conselho, a considerar, como exemplo, o deslocamento da competência do presidente do órgão, para o vice-presidente e demais membros da mesa diretora toda vez que o ato de homologação ultrapassar o prazo de 72 horas, prazo este previsto pela XI CNS para a devida publicidade da resolução, sem prejuízo das demais sanções civis e penais cabíveis;

4) considerando a legitimação do Ministério Público para o enfrentamento preventivo ou curativo, judicial ou extrajudicialmente, seja comunicado da omissão do Poder Público todas as vezes que as decisões do Consetho de Saúde deixarem de ser homologadas ou não sejam produzidos os demais atos administrativos que lhe são próprios para a devida eficiência e execução;

5) sejam criados canais de divulgação para as decisões dos ConseIhos de Saúde, facilitando o conhecimento do conteúdo das deliberações pela sociedade;

6) se efetive melhor cooperação entre os Tribunais de Contas e os Conselhos de Saúde;

7) haja mais celeridade na aproximação entre Ministério Público e Conselhos de Saúde, cuja efetivação resultará numa melhor visão da missão de cada um, aperfeiçoando o Sistema;

8) as ações e serviços de saúde, enquanto integrantes do rol de atividades-fim do Estado Democrático de Direito, devem ser tidas como prioridade nos planejamentos e gerenciamentos para a área, devendo haver disponibilização do direito à saúde, com acesso fácil, de forma universal e gratuita, sem distinção de pessoas ou classes, para todos, sendo, pois exigível, como direito público subjetivo, contra o Estado e entes privados encarregados de prestá-los; 
9) o conceito de ações e serviços de relevância pública, expresso no art. 197 da nossa Lei Maior, implica o interesse primário do Estado e o poder de controle pela sociedade, visando zelar pela efetiva prestação e por sua qualidade;

10) considerando, do Texto Constitucional, que as ações e os serviços de saúde são de relevância pública, o que lhes garante prioridade em relação aos demais serviços geridos pela administração, não pode o Estado-gestor alegar falta de recursos para a área de saúde sempre que possuir recursos para financiar outros serviços públicos menos relevantes;

11) existentes os recursos orçamentários, a garantia do direito às ações e serviços de saúde se vinculam ao cumprimento do dever constitucional por parte dos gestores, de um lado, e da atuação dos mecanismos de controle social, de outro. Sempre que o Estado-gestor desrespeitar a relevância pública dos serviços e ações de saúde, priorizando áreas menos importantes, cumpre aos mecanismos de controle entrar em campo para a devida atuação;

12) merece acolhida o pensamento de José Geraldo Brito Filomeno ao doutrinar que: "A qualidade de todo ser humano, como destinatário final do bem comum de qualquer Estado, o habilita a ver reconhecida toda a gama de seus direitos individuais e sociais, mediante tutelas adequadas colocadas à sua disposição pelos organismos institucionalizados, bem como a prerrogativa de organizar-se para obter esses resultados ou acesso àqueles meios de proteção e defesa";

13) é preciosa a lição do Promotor de Justiça Jairo Bisol ao frisar: "Os Conselhos atuam especificamente no controle político-administrativo. $O$ Ministério Público, além da atuação político-administrativa, seja no acompanhamento das políticas de saúde, na mediação de conflitos através de termos de ajustamento de condutas, ou mesmo na fiscalização do sistema de saúde, dispõe ainda de mecanismos judiciais de atuação, tais como as ações civis públicas e as ações de improbidade administrativa".

14) todas as demais ações e atos capazes de gerar o bem comum e a justiça social para todos, de iniciativa própria ou provocado.

15) Por último, merece registro ainda a bem lançada conclusão de Carlos Brito, quanto a independência administrativa e funcional do Ministério Público e a sua legitimação para agir: "não é necessário que o Ministério Público seja um Poder para que nos orgulhemos dele e para que reconheçamos o papel eminente que a Constituição lhe reservou. Acontece que nas linhas da Constituição efetivamente o Ministério Público não é poder. Nas entrelinhas, porém, não há como negar ao Ministério Público a condição de não órgão do Poder, mas órgão-poder... Nas entrelinhas, no espírito da Constituição, na alma da Constituição se chega a essa clara inferência de que o Ministério Público é um Poder estatal, porque os elementos constitu- 
cionais que dão a cada Poder a sua configuração, a sua identidade, estão presentes no Ministério Público. O Ministério Público não precisa de lei. Ele atua imediatamente os comandos constitucionais, ele de ofício aplica a própria Constituição e na técnica jurídica isso se chama governar".

\section{REFERÊNCIAS BIBLIOGRÁFICAS}

BISOL, Jairo. PROSUS - Guia do Conselheiro de Saúde: Ministério Público e controle social. Brasília: Ministério da Saúde, 2002.

DALLARI, Sueli Gandolfi. Direito sanitário. In: MANUAL Conceitual do Curso de Especialização a distância em Direito Sanitário, para membros do Ministério Público e da Magistratura Federal. Brasília: Ed. UnB; FIOCRUZ.

FILOMENO, José Geraldo Brito. MP - Instituições e processo. São Paulo: Atlas, 1997.

GUIA do Conselheiro. Curso de Capacitação de Conselheiros Estaduais e Municipais - 2002-MS.

MELLO, Celso. STF-Pleno-MS/SP 22.164. Diário da Justiça, Seção I, 17 nov. 1995.

MINISTÉRIO DA SAÚDE. Curso de capacitação de Conselheiros. Brasília: 2002.

MORAES, Alexandre. Direito constitucional. 6. ed. São Paulo: Atlas, 1999.

SALVETTI NETTO, Pedro. Curso de ciência política. São Paulo: Hemeron Ed., 1977.

SANTANA, Edílson Gonçalves. O Ministério Público no Estado democrático de direito. Fortaleza: Ed. ABC, 2000. 